\title{
Table of national instruments
}

1863 Instructions for the Government of Armies of the United States in the Field, prepared by Francis Lieber, promulgated as General Orders No. 100, by President Lincoln, 24 April 1863 (Lieber Code), reprinted in D. Schindler and J. Toman, The Laws of Armed Conflicts: A Collection of Conventions, Resolutions and other Documents (Dordrecht: Nijhoff, 1998), p. 3

1988 Genocide Convention Implementation Act (Proxmire Act), 18 USC, Chapter 50A, $\$ 1091-3$, reprinted in L. LeBlanc, The United States and the Genocide Convention (Durham NC: Duke University Press, 1991), p. 255

2000 Crimes against Humanity and War Crimes Act, 2000, C.24, available at: $<$ http://laws.justice.gc.ca/en/e-45.9/38374.html>

2001 International Criminal Court Act, 2001, available at: <http://www. legislation.hmso.gov.uk/acts/acts2001/20010017.htm>

2001 International Criminal Court (Scotland) Act, 2001, available at: <http://www. scotland-legislation.hmso.gov.uk/legislation/scotland/s-acts.htm>

2002 Act to Introduce the Code of Crimes against International Law, 2002, translated by B. Duffett, available at: <http://www.iccnow.org/resourcestools/ratimptoolkit/ nationalregionaltools/legislationdebates.html>

2002 International Criminal Court (Consequential Amendments) Act, 2002, No. 42, Schedule 1, Amendment of the Criminal Code Act, 1995, available at: <http:// scaleplus.law.gov.au/html/comact/browse/TOCN.htm> 